\title{
Low Overpotential, High Activity: Manganese/ Ruthenium mixed Oxide Electrocatalysts for Oxygen Evolution in Alkaline media
}

\author{
Michelle P. Browne $^{\mathrm{a}, \mathrm{b}^{*}}$, Paula E. Colavita ${ }^{\mathrm{a}, \mathrm{b}}$ and Michael E.G Lyons ${ }^{\mathrm{a}, \mathrm{b}}$ \\ a School of Chemistry, Trinity College Dublin, College Green, Dublin 2, Ireland \\ ${ }^{\mathrm{b}}$ Centre for Research on Adaptive Nanostructures and Nanodevices (CRANN)
}

The combination of a platinum group material (i.e. ruthenium) with a first row transition metal (i.e. manganese) could provide stability and lower the cost of OER electrocatalyst, while still obtaining good OER properties. In this work classical electrochemical techniques have been used to study the electrocatalytic properties of thermally prepared manganese, mixed manganese/ruthenium and ruthenium based electrocatalysts on a titanium substrate at three different annealing temperatures for OER. The structure and morphology of the thermally decomposed oxide materials are examined using Scanning Electron Microscopy (SEM) and Fourier Transform Infrared (FTIR) spectroscopy. Turnover Frequency (TOF) numbers are also calculated. The initial OER overpotential values of eight electrocatalysts, in this study, are lower than that of the lowest known OER electrocatalyst, $\mathrm{RuO}_{2}$. All SEM images with $10-100 \%$ of $\mathrm{RuO}_{\mathrm{x}}$ show a mud-cracked morphology. This morphology is attributed to the excellent electrocatalytic activity of $\mathrm{RuO}_{2}$.

\section{Introduction}

Hydrogen, as an energy carrier, has become increasingly important in the last few decades as the interest in developing a clean, renewable energy source has significantly risen due to the future uncertainty of the availability of fossil fuels. In addition to their limited availability, fossil fuels also release undesirable carbon-based gases into the earth's atmosphere when burnt. Molecular hydrogen is one energy alternative that is predicted to become a frontier technology in the future battle to cater for our energy demands (1). This is due to molecular hydrogen being a clean energy fuel which exhibits a higher gravimetric energy density value than its alternatives. Currently, steam reforming of natural gas is the primary industrial route used to produce molecular hydrogen (2). A disadvantage of using natural gas is that methane is its main component, which contains the same drawbacks as fossil fuels. Alkaline water electrolysis has been proposed as an environmentally inoffensive and reliable solution to this problem. In contrast to fossil fuels, the only waste product from this energy-production route is water.

Alkaline water electrolysis produces pure hydrogen gas, which can be used for energy storage or combusted in energy devices, such as fuel cells, to produce energy. This is the basis of the so-called hydrogen economy (3-5). Currently, the efficiency of this technology is limited by a large anodic overpotential associated with the oxygen evolution reaction (OER) (3). Consequently, a vast amount of research is currently dedicated to understanding the OER and the materials used in producing OER electrocatalysts. 
One type of electrocatalysts being studied to overcome these large overpotentials is Dimensionally Stable Anodic (DSA ${ }^{\circledR}$ ) electrodes. DSA ${ }^{\circledR}$ electrodes usually consist of an inert support, i.e. titanium, coated with a metal oxide to catalyse the OER. For this reaction, the optimum metal oxide materials are ruthenium and iridium oxides, due to their ability to produce the lowest known OER overpotential. However, these materials have not been commercialized as the raw materials used to produce these oxides are expensive and corrode easily in alkaline media; which render these materials both impractical and uneconomical.

In this study, a platinum based group material (ruthenium) and a first row transition metal oxide material (manganese) were studied in pure and mixed forms over three annealing temperatures. The mixed manganese and ruthenium oxide electrocatalysts included five molar ratios, 90:10, 75:25, 50:50, 25:75 and 10:90, which are also investigated over the same annealing temperature range. The combination of a platinum based material (ruthenium) with a first row transition metal (manganese) could provide stability for the electrode compared to the pure ruthenium electrode and lower the cost of the overall electrocatalyst, whilst maintaining the characteristics of a desirable OER electrocatalyst. In this work, classical electrochemical, spectroscopic and microscopic techniques have been used to study the electrocatalytic properties of thermally prepared pure manganese, manganese ruthenium mixed and pure ruthenium based electrocatalysts.

The different electrocatalysts were compared and contrasted under a number of Key Performance Indicators (KPI's); namely, cost, OER overpotential, Tafel slope values and TOF.

\section{$\underline{\text { Experimental Procedure }}$}

\section{$\underline{\text { Materials and Reagents }}$}

The materials and reagents used in these experiments were titanium wire (Alfa Aesar- Johnson Matthey company, 99.99\% (metals basis), diameter of $1 \mathrm{~mm}$ )), sulfuric acid (Sigma Aldrich, 95-97\%, analytical grade), aluminum powder (Sigma Aldrich), 1200 grit carbimet paper (Buehler), manganese acetate (Sigma Aldrich, $\geq 99 \%$ metal basis, M. $245.09 \mathrm{~g} / \mathrm{mol}$ ), ruthenium chloride (Sigma Aldrich, 99.98\% metal basis, M. 245.09 $\mathrm{g} / \mathrm{mol}$ ), butanol (Sigma Aldrich, $\geq 99 \%$, reagent- grade), mercury-mercuric oxide $(\mathrm{Hg} / \mathrm{HgO})$ reference electrode $(\mathrm{CH}$ instruments, cat no. 152), sodium hydroxide pellets (Sigma-Aldrich, $\geq 98 \%$, reagent-grade), carbon tabs (Agar Scientific), copper tape (Agar Scientific), potassium bromide powder (Sigma Aldrich).

\section{Preparation of Thermally Prepared Metal Oxide Electrocatalysts on Ti films}

All of the working electrodes described in this work were prepared using a thermal decomposition method, as outlined by Galizzioli et al. (6). To prepare the electrodes, titanium wire was partially encapsulated in glass. The electrodes were then dipped in $5 \mathrm{M}$ $\mathrm{H}_{2} \mathrm{SO}_{4}$, polished with aluminum powder and 1200 grit carbimet paper, washed with deionized water and set aside to dry. This cleaning process was carried out numerous of times until a shiny bright finish was observed.

Seven 0.2 M precursor solutions were made by dissolving different ratios of $\left(\mathrm{CH}_{3} \mathrm{COO}\right)_{2} \mathrm{Mn} \cdot 4 \mathrm{H}_{2} \mathrm{O}$ and $\mathrm{RuCl}_{3} \cdot \mathrm{xH}_{2} \mathrm{O}$, in butanol, in separate $10 \mathrm{ml}$ conical flasks (weighed out using a Sartorius, model 1872 balance). The resulting mixtures were evaporated on a hotplate (Jenway hotplate and stirrer, model 1000) until minimal solvent 
remained in the conical flask. This formed the metal oxide paste which was used to prepare the working electrodes.

The annealing treatment used in this research consisted of painting the working electrode with one coat of the relevant paste and drying in an oven at $90{ }^{\circ} \mathrm{C}$ for ten minutes in air. Subsequent coats of the paste were applied to the electrode until a homogenous layer covered the titanium wire. The resulting electrode was annealed in air, in a second oven, for nine hours. The seven different materials were used to prepare the electrocatalysts (manganese, manganese/ruthenium and ruthenium) at various annealing temperatures $\left(350^{\circ} \mathrm{C}, 450{ }^{\circ} \mathrm{C}\right.$ and $\left.600{ }^{\circ} \mathrm{C}\right)$ on the titanium wire.

\section{$\underline{\text { Physical Characterisation }}$}

\section{$\underline{\text { Scanning Electron Microscopy }}$}

The morphological characteristics of the DSA ${ }^{\circledR}$ type electrodes were determined using a Karl Zeiss Ultra Field Emission scanning electron microscope at an accelerating voltage between $15 \mathrm{KeV}-2 \mathrm{KeV}$ at a working distance of between $9 \mathrm{~mm}-5 \mathrm{~mm}$.

\section{Fourier Transform Infrared Spectroscopy}

FTIR Spectroscopic analysis was also carried out on the DSA ${ }^{\circledR}$ type electrodes using a Spectrum 100 FTIR spectrometer with Spectrum software to record the data. The Spectra were recorded in the range between $4000 \mathrm{~cm}^{-1}$ and $500 \mathrm{~cm}^{-1} . \mathrm{KBr}$ pellets were used for the FTIR analysis, in a KBr: sample ratio of 100:1.

\section{Electrochemical Methodology}

\section{Electrochemical Setup}

All electrochemical experiments were undertaken in a standard three-electrode cell. The working electrodes consisted of the titanium film substrate with a metal salt paste annealed at different temperatures, as described in the section above. A graphite rod was employed as a counter-electrode and a mercury-mercuric oxide $(\mathrm{Hg} / \mathrm{HgO})$ reference electrode was used as a reference standard. All potential voltages are quoted with respect to the $(\mathrm{Hg} / \mathrm{HgO})$ reference electrode, unless otherwise stated. The various electrolyte solutions used for the redox behavior studies of the different electrocatalysts produced, including Tafel slope analysis were prepared from $\mathrm{NaOH}$ pellets. The concentrations of the $\mathrm{NaOH}$ electrolyte solutions ranged from $0.01 \mathrm{M}$ to $5 \mathrm{M}$. Electrochemical measurements were taken at a constant temperature of $25{ }^{\circ} \mathrm{C}$, using a thermal bath with the temperature maintained by a thermostat. All solutions were degassed for 15 minutes before commencing any analysis, to eliminate any dissolved oxygen present in the electrolyte.

\section{Cyclic Voltammetry (CV)}

Cyclic voltammetry (CV) experiments were conducted in aqueous $1.0 \mathrm{M} \mathrm{NaOH}$ at $100 \mathrm{mV} \mathrm{s}^{-1}$ between the limits of $-0.6 \mathrm{~V}$ and $+0.8 \mathrm{~V}$ vs. $\mathrm{Hg} / \mathrm{HgO}$ reference electrode. The $\mathrm{CV}$ measurements were performed using a high performance digital potentiostat $(\mathrm{CH}$ 
model 1760 D Bi-potentiostat system monitored using CH1760D electrochemical workstation beta software).

\section{$\underline{\text { Tafel Plot Measurements }}$}

Tafel plot measurements were performed at a sweep rate of $1 \mathrm{mV} \mathrm{s}^{-1}$ in the forward oxidation direction. For Tafel plot measurements, the uncompensated solution resistance was usually determined at a $90 \%$ compensation level. All Tafel plot data are presented in $\mathrm{iR}$ compensated form, explained in Section 2.3.5. Tafel Plot measurements were also performed using a $\mathrm{CH}$ model $1760 \mathrm{D}$ Bi-potentiostat system monitored by CH1760D electrochemical workstation beta software.

\section{$\underline{\text { Results and Discussion }}$}

\section{$\underline{\text { Physical Characterisation }}$}

Scanning Electron Microscopy (SEM) images were obtained for the various thermally prepared electrocatalysts prepared using different molar ratios of manganese and ruthenium oxides at an annealing temperature if $350{ }^{\circ} \mathrm{C}$, Figure 1 . The pure $100 \%$ manganese electrocatalyst exhibits a flower like morphology; whereas the pure $100 \%$ ruthenium electrocatalyst exhibits a mud cracked-like morphology. Interestingly, the SEM images, Figure 1 (b-e), show that the electrocatalysts containing any amount of ruthenium oxide illustrate a mud-cracked morphology.

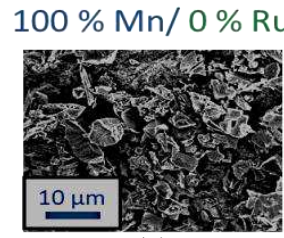

(a)

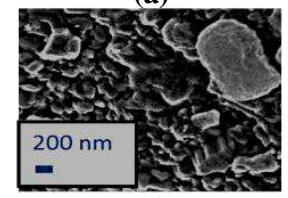

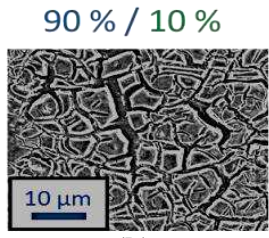

(b)

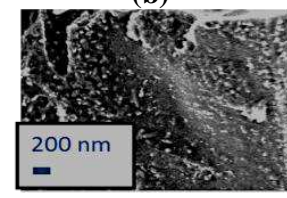

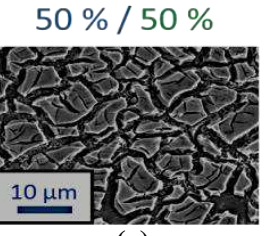

(c)

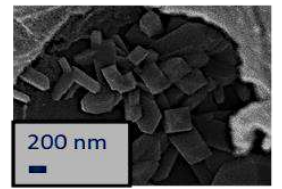

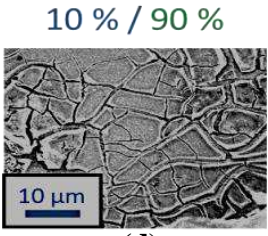

(d)

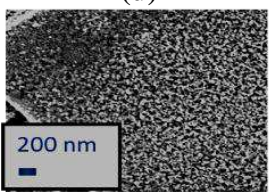

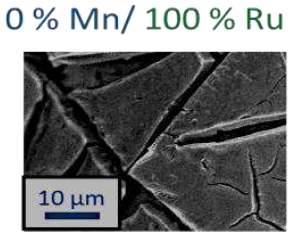

(e)

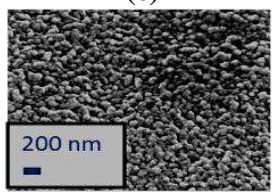

Figure 1. High and Low Magnification SEM images for electrocatalysts containing a manganese oxide molar percentage of (a) $100 \%$ (b) $90 \%$ (c) $50 \%$ (d) 10 and (e) $0 \%(100 \%)$ ruthenium oxide

This mud cracked morphology has been previously observed by other authors for ruthenium oxide electrocatalysts.(7) Lower magnifications, of approximately $200 \mathrm{~nm}$ reveal the morphology of the $\mathrm{RuO}_{2}$ electrocatalyst contains nanoscale particles on the surface of the cracked-like surface, as shown in Figure 1(e). The lower Tafel slopes and overpotential values attributed to the $\mathrm{RuO}_{\mathrm{x}}$ electrocatalysts may be attributed to these nanoscale particles as a larger surface area is exposed. A larger surface area would suggest there are more OER active sites on the electrocatalyst, improving the overall electrocatalytic activity of these electrocatalysts.

When the morphologies of the pure $\mathrm{Mn}_{\mathrm{x}} \mathrm{O}_{\mathrm{y}}$ electrocatalysts at the different annealing temperatures were examined, the images show that there is a significant change in the morphology, especially between the annealing temperatures of 350 and the $600{ }^{\circ} \mathrm{C}$, 
Figure 2. This change in morphology could suggest a change in composition of the manganese oxide.
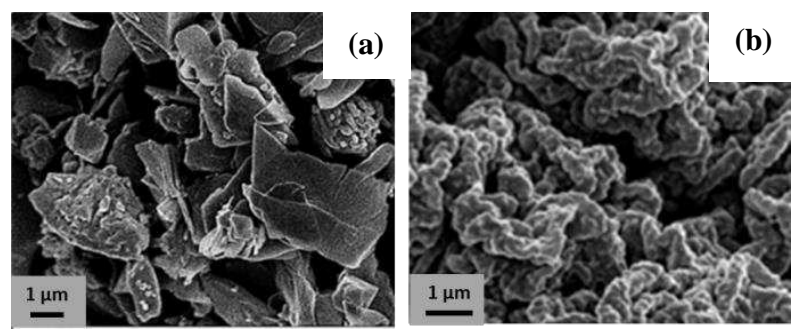

Figure 2.Pure $100 \%$ manganese oxide electrocatalyst at an annealing temperature of (a) $350{ }^{\circ} \mathrm{C}$ and (b) $600{ }^{\circ} \mathrm{C}$.

Nohman et al. explored the decomposition of manganese acetate through various techniques, including FTIR spectroscopy and X-Ray Diffraction (XRD) (8). Their results indicated that at an annealing temperature of $350{ }^{\circ} \mathrm{C}, \mathrm{Mn}_{3} \mathrm{O}_{4}$ was produced. By applying a higher annealing temperature of $550{ }^{\circ} \mathrm{C}$, this caused further thermal decomposition of $\mathrm{Mn}_{3} \mathrm{O}_{4}$ to $\mathrm{Mn}_{2} \mathrm{O}_{3}$. These results could suggest the difference in the morphology between the thermally prepared pure $\mathrm{Mn}_{\mathrm{x}} \mathrm{O}_{\mathrm{y}}$ at the annealing temperatures of $350{ }^{\circ} \mathrm{C}$ and $600{ }^{\circ} \mathrm{C}$.

SEM-Energy Dispersive EDX analysis indicates that the manganese/ruthenium films are not homogenous on the Ti substrate, Figure 3. The raised surfaces between the cracks are dominated by ruthenium, Figure 3(a). Interestingly, it seems the titanium substrate can be observed between these raised surfaces, Figure 3(d), however the manganese appears to be in a uniform layer on the surface of the substrate, Figure 3(c).
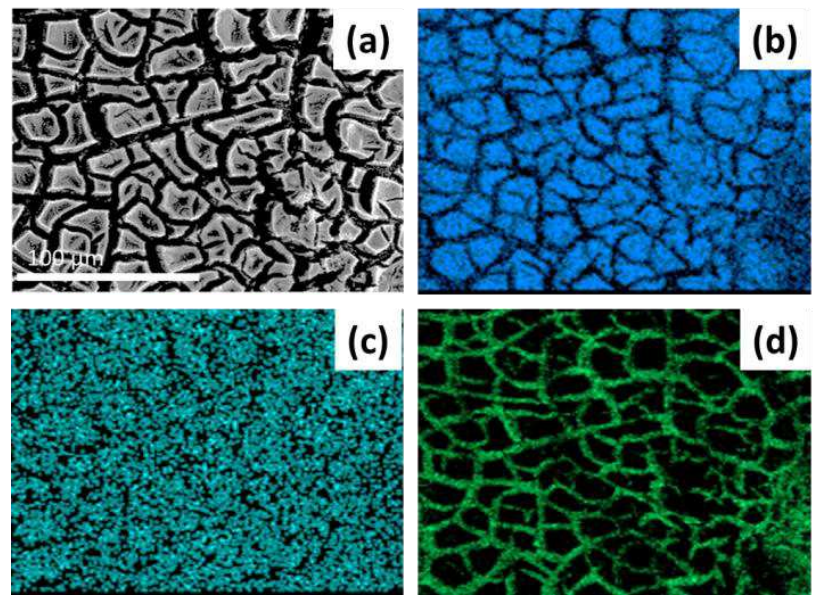

Figure 3(a) SEM image with corresponding EDX mapping of (b) ruthenium (c) manganese and (d) titanium.

Powder FTIR was utilized to investigate the different composition of the electrocatalytic material in this work. The FTIR spectra of the $\mathrm{Mn}_{\mathrm{x}} \mathrm{O}_{\mathrm{y}}$ oxide electrocatalysts are shown in Figure 4. At the lowest annealing temperature used $\left(350{ }^{\circ} \mathrm{C}\right)$, the peak observed at $514 \mathrm{~cm}^{-1}$ is attributed to the $\mathrm{Mn}-\mathrm{O}$ vibrational mode in the octahedral lattice environment of the $\mathrm{Mn}_{3} \mathrm{O}_{4}$ structure. The vibrational mode at $616 \mathrm{~cm}^{-1}$ can be assigned to the $\mathrm{Mn}-\mathrm{O}$ bond in the tetrahedral environment of the $\mathrm{Mn}_{3} \mathrm{O}_{4}$. These peaks are consistent with FTIR peaks assigned to $\mathrm{Mn}_{3} \mathrm{O}_{4}$ in the literature (9-10) At the 
lower end of the fingerprint region, a small vibrational peak at $447 \mathrm{~cm}^{-1}$ is attributed to a vibrational mode belonging to $\mathrm{Mn}_{2} \mathrm{O}_{3}$, however, this peak is very weak (11-12). The FTIR spectrum of the manganese oxide compound formed at $450{ }^{\circ} \mathrm{C}$ can also be assigned to the coupling between the Mn-O vibration modes at the wavenumbers of $497 \mathrm{~cm}^{-1}$ and $608 \mathrm{~cm}^{-1}$ for the octahedral and tetrahedral sites on $\mathrm{Mn}_{3} \mathrm{O}_{4}$, respectively. The weak vibrational peak at $451 \mathrm{~cm}^{-1}$ can, again, be assigned to $\mathrm{Mn}_{2} \mathrm{O}_{3}$; this peak is also observed at an annealing temperature of $450{ }^{\circ} \mathrm{C}$. At an annealing temperature of $600{ }^{\circ} \mathrm{C}$, the peaks observed at $532 \mathrm{~cm}^{-1}$ can be attributed to $\mathrm{Mn}-\mathrm{O}$ bending vibrations of $\mathrm{Mn}_{2} \mathrm{O}_{3}$, while those at $573 \mathrm{~cm}^{-1}$ and $673 \mathrm{~cm}^{-1}$ can be assigned to the Mn-O stretching vibrational modes of $\mathrm{Mn}_{2} \mathrm{O}_{3}(13-14)$.

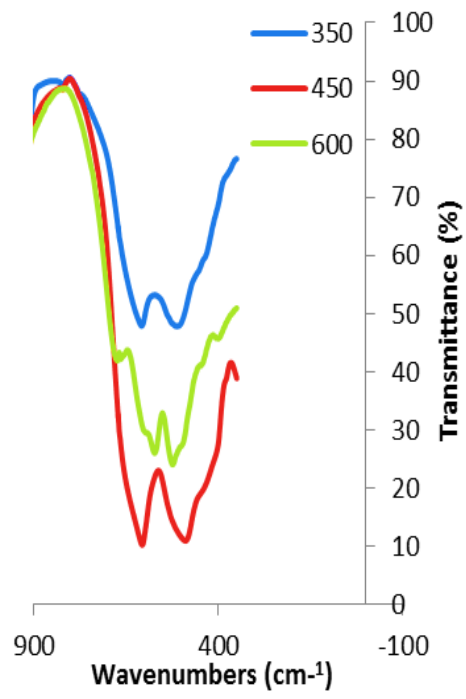

Figure 4.FTIR spectra of manganese oxides

FTIR analysis reveals that, at the lowest temperature of $350{ }^{\circ} \mathrm{C}$, the $\mathrm{Mn}_{\mathrm{x}} \mathrm{O}_{\mathrm{y}}$ formed is predominately $\mathrm{Mn}_{3} \mathrm{O}_{4}$ with minimal amounts of $\mathrm{Mn}_{2} \mathrm{O}_{3}$. As the annealing temperature increases to $450{ }^{\circ} \mathrm{C}$, the vibrational $\mathrm{Mn}_{2} \mathrm{O}_{3}$ peak (ca. $451 \mathrm{~cm}^{-1}$ ) in the FTIR spectrum is marginally enhanced, indicating that the amount of $\mathrm{Mn}_{2} \mathrm{O}_{3}$ formed has increased, although still minimal amounts. The FTIR spectrum at $600^{\circ} \mathrm{C}$ shows the predominant formation of $\mathrm{Mn}_{2} \mathrm{O}_{3}$.

\section{$\underline{\text { Electrochemical Evaluation of Electrocatalysts for OER }}$}

Cyclic voltammetry was used to study the redox properties of the thermally prepared pure $\mathrm{Mn}_{\mathrm{x}} \mathrm{O}_{\mathrm{y}}$, pure $\mathrm{RuO}_{\mathrm{x}}$ and the $\mathrm{Mn}_{\mathrm{x}} \mathrm{O}_{\mathrm{y}} / \mathrm{RuO}_{\mathrm{x}}(90: 10,75: 25,50: 50,25: 75$ and 10:90) mixed electrodes at the different annealing temperatures. Changes in annealing temperatures and material used resulted in different voltammetric profiles for the same metal substrate. This change could be due to different compounds and/or morphologies formed on the substrate at different temperature using the various materials. For example, the variation in redox properties for different materials annealed at $350{ }^{\circ} \mathrm{C}$ used can be observed in the cyclic voltammograms below, Figure 5. 
$100 \%$ Ru oxide

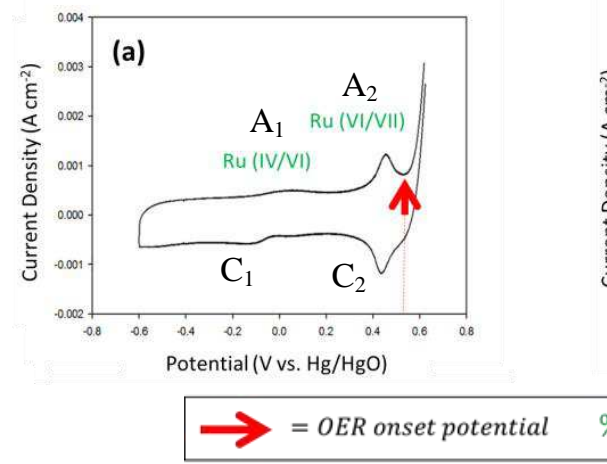

$50 \% / 50 \%$

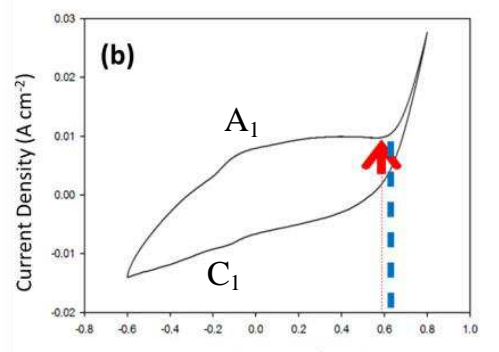

Potential (V vs. $\mathrm{Hg} / \mathrm{HgO})$
$100 \%$ Mn oxide

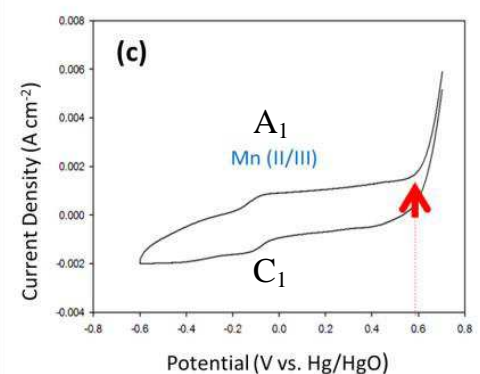

Figure 5.Cyclic Voltammogram profiles of electrocatalysts annealed at $350{ }^{\circ} \mathrm{C}$ from (a) Pure (100 \%) Ru (b) 50:50 Mn:Ru and (c) Pure (100\%) Mn

Thermally prepared $\mathrm{RuO}_{\mathrm{x}}$ has three distinctive and well established redox processes in base, which involve the surface transitions of $\mathrm{Ru}$ (III/IV), $\mathrm{Ru}$ (IV/VI) and finally $\mathrm{Ru}$ (VI/VII) (15). Two of these transitions can be observed in the voltammetric profiles, as observed in Figure. 5(a). The pure (100\%) $\mathrm{RuO}_{\mathrm{x}}$ coated on the Ti substrate produced two sets of oxidation and reduction peaks at the annealing temperature of 350 ${ }^{\circ} \mathrm{C}$. The first set of redox peaks, denoted as $\mathrm{A}_{1} / \mathrm{C}_{1}$, in Figure 5(a), are characteristic of the $\mathrm{Ru}(\mathrm{IV} / \mathrm{VI})$ redox transition, which occurs at an anodic potential of ca. $0.1 \mathrm{~V}$ and cathodic potential of ca. $-0.1 \mathrm{~V}$. This reaction in alkaline solution is described as follows:

$$
\mathrm{RuO}_{2}+4 \mathrm{OH}^{-} \rightarrow \mathrm{RuO}_{4}^{--}+2 \mathrm{H}_{2} \mathrm{O}+2 \mathrm{e}^{-}
$$

The set of well-defined peaks observed at a potential of $+0.45 \mathrm{~V}\left(\mathrm{~A}_{2} / \mathrm{C}_{2}\right)$ prior to the onset of oxygen evolution, Figure 7 , is a very distinguishable and irreversible redox process involving the oxidation of $\mathrm{Ru}$ (VI) to $\mathrm{Ru}$ (VII). This redox process is only observed in alkaline media (16-17). The following equation describes this irreversible redox process:

$$
\mathrm{RuO}_{4}^{--} \rightarrow \mathrm{RuO}_{4}^{-}+\mathrm{e}^{-}
$$

The pure $(100 \%) \mathrm{Mn}_{\mathrm{x}} \mathrm{O}_{\mathrm{y}}$ material on $\mathrm{Ti}$ at $350{ }^{\circ} \mathrm{C}$ exhibits one oxidation peak at a potential of ca. $-0.1 \mathrm{~V}\left(\mathrm{~A}_{1}\right)$ and one reduction peak at a potential ca. of $0.0 \mathrm{~V}\left(\mathrm{C}_{1}\right)$., Figure 5(c). $\mathrm{Mn}_{\mathrm{x}} \mathrm{O}_{\mathrm{y}}$ species are widely known to be complex and their assignment of the specific manganese oxide species is difficult, due to the wide range of oxidation states available for manganese. We proposed that the following redox reaction of $\mathrm{Mn}$ (II/III) could be taking place at the $\mathrm{A}_{1} / \mathrm{C}_{1}$ redox peaks at a potential of $0.1 \mathrm{~V}$, as shown in Figure 5(c). These redox transitions can be written as follows:

$$
\begin{array}{r}
3 \mathrm{MnO}+2 \mathrm{OH}^{-} \rightarrow \mathrm{Mn}_{3} \mathrm{O}_{4}+\mathrm{H}_{2} \mathrm{O}+\mathrm{e}^{-} \\
2 \mathrm{Mn}_{3} \mathrm{O}_{4}+2 \mathrm{OH}^{-} \longrightarrow 3 \mathrm{Mn}_{2} \mathrm{O}_{3}+\mathrm{H}_{2} \mathrm{O}+2 \mathrm{e}^{-}
\end{array}
$$

Each of the reactions above, [3] and [4], could happen in unison or separately depending on the initial type of $\mathrm{Mn}_{\mathrm{x}} \mathrm{O}_{\mathrm{y}}$ produced on the Ti film. 
OER Tafel slope values and the OER onset overpotential also vary with the change in material and annealing temperature applied to the electrocatalyst. Typical OER Tafel slope values are shown in Figure 6. The Tafel slope is defined as the change in sensitivity of the current over the driving force (or overpotential). Subsequently, the higher the Tafel slope value of an electrocatalyst indicates that the electrocatalyst is less electrocatalytic active compared to an electrocatalyst with a lower Tafel slope value.

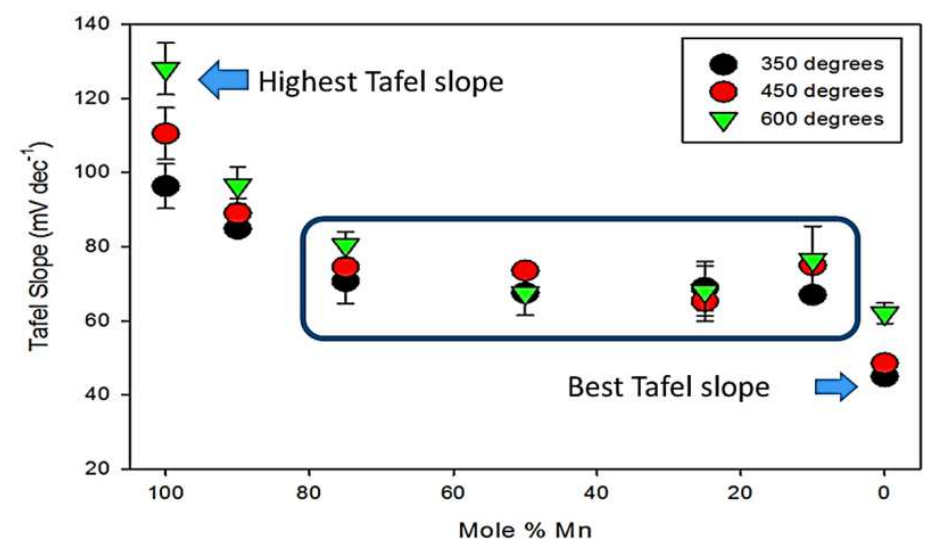

Figure 6.OER Tafel slope values for electrocatalysts

The material that exhibits the highest Tafel slope, the least catalytically active material, is the pure $(100 \%) \mathrm{Mn}_{\mathrm{x}} \mathrm{O}_{\mathrm{y}}$, exhibiting a Tafel slope of $128 \pm 7 \mathrm{mV} \mathrm{dec}^{-1}$, Figure 6. This shows that, for this material, increasing annealing temperature makes the electrocatalyst become less active for the OER. This may result from distinct manganese compounds formed at the various annealing temperatures. The change in composition in the manganese oxide compounds can be observed in the FTIR results, Figure 4. Previously it has been found that the thermal treatment of manganese oxides at higher temperatures decreased the conductivity of the electrocatalyst due to the formation of excess $\mathrm{Mn}_{2} \mathrm{O}_{3}(10)$.

FTIR analysis reveals that, at the lowest temperature of $350{ }^{\circ} \mathrm{C}$ the $\mathrm{Mn}_{\mathrm{x}} \mathrm{O}_{\mathrm{y}}$ formed is predominately $\mathrm{Mn}_{3} \mathrm{O}_{4}$ with perhaps a slight amount of $\mathrm{Mn}_{2} \mathrm{O}_{3}$. As the annealing temperature increases to $450{ }^{\circ} \mathrm{C}$, the vibrational $\mathrm{Mn}_{2} \mathrm{O}_{3}$ peak $\left(\mathrm{ca} .451 \mathrm{~cm}^{-1}\right.$ ) in the FTIR spectrum is marginally enhanced, indicating that the amount of $\mathrm{Mn}_{2} \mathrm{O}_{3}$ formed has increased, although still minimal amounts. The FTIR spectrum at $600{ }^{\circ} \mathrm{C}$ shows the predominant formation of $\mathrm{Mn}_{2} \mathrm{O}_{3}$. It is certainly possible that with increasing annealing temperature, the Tafel slopes increases as more $\mathrm{Mn}_{2} \mathrm{O}_{3}$ is formed, reducing the electrical conductance of the electrocatalyst.

With the addition of $10 \% \mathrm{RuO}_{\mathrm{x}}$ to the $\mathrm{Mn}_{\mathrm{x}} \mathrm{O}_{\mathrm{y}}$ the Tafel Slope values decrease compared to the pure $\mathrm{Mn}_{\mathrm{x}} \mathrm{O}_{\mathrm{y}}$. Interestingly, the morphology of the 90:10 $\mathrm{Mn}_{\mathrm{x}} \mathrm{O}_{\mathrm{y}}: \mathrm{RuO}_{\mathrm{x}}$ electrocatalyst also has the mud-cracked morphology similar to the pure (100\%) $\mathrm{RuO}_{2}$, Figure 1 (b); which previous authors believe contributes to $\mathrm{RuO}_{2}$ exhibiting the lowest known OER Tafel slope (15). The $\mathrm{Mn}_{\mathrm{x}} \mathrm{O}_{\mathrm{y}}: \mathrm{RuO}_{\mathrm{x}}$ electrocatalysts containing between $75-$ 10 mole percentage $\mathrm{Mn}$ results in diminishing returns for the overall production for the electrocatalysts with the higher $\mathrm{RuO}_{\mathrm{x}}$ content. These electrocatalysts exhibit similar Tafel slopes while the cost of making the catalysts increase as the mole percentage of $\mathrm{RuO}_{\mathrm{x}}$ increases, Figure 6 . The 75:25 $\mathrm{Mn}_{\mathrm{x}} \mathrm{O}_{\mathrm{y}}: \mathrm{RuO}_{\mathrm{x}}$ electrocatalyst, when considering Tafel slope values, would prove to be the most economical from the aforementioned subset of 
electrocatalysts due to its lower cost of production while maintaining a similar Tafel slope compared with the higher $\mathrm{RuO}_{\mathrm{x}}$ mole percentage content electrocatalysts.

Unsurprisingly, the electrocatalyst with the lowest Tafel slope in this work was the $\mathrm{RuO}_{\mathrm{x}}$ annealed at $350{ }^{\circ} \mathrm{C}$; with a value of $40 \pm 2 \mathrm{mV} \mathrm{dec}{ }^{-1}$. As previously mentioned, the low Tafel slopes of ruthenium and iridium oxide electrodes may be attributed to the mud-cracked morphology, Figure 1 (e), in which this material displays on a substrate (17).

Typical OER overpotential values for all the electrocatalysts in this work are given in Figure 7. The lower the overpotential value for an electrocatalyst the better, as less energy is being applied to the system for OER to occur. Currently $\mathrm{RuO}_{2}$ and $\mathrm{IrO}_{2}$ exhibit the lowest overpotential for the evolution of oxygen, with initial OER overpotential values of $0.2 \mathrm{~V}(18)$.

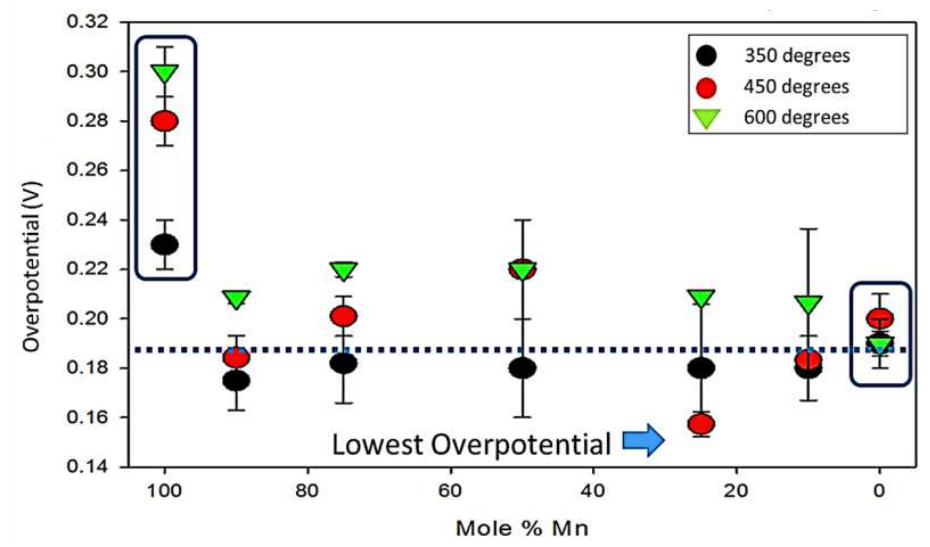

Figure 7.Initial OER overpotential values for electrocatalysts

For the pure (100\%) $\mathrm{Mn}_{\mathrm{x}} \mathrm{O}_{\mathrm{y}}$ electrocatalysts the overpotential values increase with increasing annealing temperature. An annealing temperature of $350{ }^{\circ} \mathrm{C}$ exhibits the lowest overpotential when comparing the electrocatalyst produced from the pure $\mathrm{Mn}_{\mathrm{x}} \mathrm{O}_{\mathrm{y}}$ material. While the electrocatalyst annealed at $600{ }^{\circ} \mathrm{C}$ from the $\mathrm{Mn}_{\mathrm{x}} \mathrm{O}_{\mathrm{y}}$ material shows the highest overpotential, with a value of $0.30 \pm 0.01 \mathrm{~V}$. This trend may be governed by the change in composition of the $\mathrm{Mn}_{\mathrm{x}} \mathrm{O}_{\mathrm{y}}$ material produced at the various annealing temperatures. The FTIR analysis, Figure 4, suggests at an annealing temperature of $350{ }^{\circ} \mathrm{C}, \mathrm{Mn}_{3} \mathrm{O}_{4}$ is formed. At subsequent temperatures more $\mathrm{Mn}_{2} \mathrm{O}_{3}$ is formed. $\mathrm{Mn}_{2} \mathrm{O}_{3}$ is less conductive than $\mathrm{Mn}_{3} \mathrm{O}_{4}$. The production of $\mathrm{Mn}_{2} \mathrm{O}_{3}$ at the higher annealing temperatures, due to the catalysts being less conductive, may be the resultant of the lower initial OER overpotential, compared with the $\mathrm{Mn}_{\mathrm{x}} \mathrm{O}_{\mathrm{y}}$ electrocatalyst produced at $350{ }^{\circ} \mathrm{C}$.

With the addition of $\mathrm{RuO}_{\mathrm{x}}$ to the $\mathrm{Mn}_{\mathrm{x}} \mathrm{O}_{\mathrm{y}}$, even in minimal amounts, the overpotential is dramatically lowered. In this work, twenty-one OER electrocatalysts were produced and studied. Of these, eight electrocatalysts exhibited lower OER overpotential than $\mathrm{RuO}_{2}$, the material with the lowest known OER overpotential to date. The 25:75 Mn:Ru electrocatalyst annealed at $450{ }^{\circ} \mathrm{C}$ has the lowest overpotential, $0.16 \pm$ $0.005 \mathrm{~V}$, this value is approximately $20 \%$ lower than that of $\mathrm{RuO}_{2}$. Inital OER overpotential values for the pure $(100 \%) \mathrm{RuO}_{\mathrm{x}}$ electrocatalyst correlate to previous results in literature (19-21).

The TOF number of an OER electrocatalysts is a measure of the electrocatalysts ability to produce oxygen. A large TOF number is advantageous, as it shows that the 
electrocatalyst is producing an increased number of moles of oxygen per active site per unit time. TOF can be calculated using to the following equation:

$$
T O F=\frac{J_{E}}{4 Q}
$$

Where $\boldsymbol{J}_{\boldsymbol{E}}$ is the current density at the potential $\boldsymbol{E}, \boldsymbol{Q}$ is the charge associated with the redox processes occurring on the electrode and the multiplication factor 4 is used as the OER is a four-electron transfer reaction (16).

Even though current density is related to the charge of the electrocatalyst and, therefore, related to the amount of material on the electrode, it is not a measure of the specific electrocatalytic ability of the OER electrocatalyst. The TOF number takes into account the reaction under analysis at the specific overpotential at which the reaction occurs.

In this work, the overpotential at which the TOF numbers where calculated was $0.4 \mathrm{~V}$ as this overpotential was in the OER region for all the electrocatalysts. The TOF values for the thermally prepared $\mathrm{Mn}_{\mathrm{x}} \mathrm{O}_{\mathrm{y}}, \mathrm{RuO}_{\mathrm{x}}$ and mixed $\mathrm{Mn}_{\mathrm{x}} \mathrm{O}_{\mathrm{y}} / \mathrm{RuO}_{\mathrm{x}}$ on Ti film at the annealing temperatures of $350{ }^{\circ} \mathrm{C}, 450{ }^{\circ} \mathrm{C}$ and $600{ }^{\circ} \mathrm{C}$ can be observed in Figure 8 and Table 1. This table shows a comparison of some of the electrocatalytic materials prepared in this work to similar materials prepared by other authors.

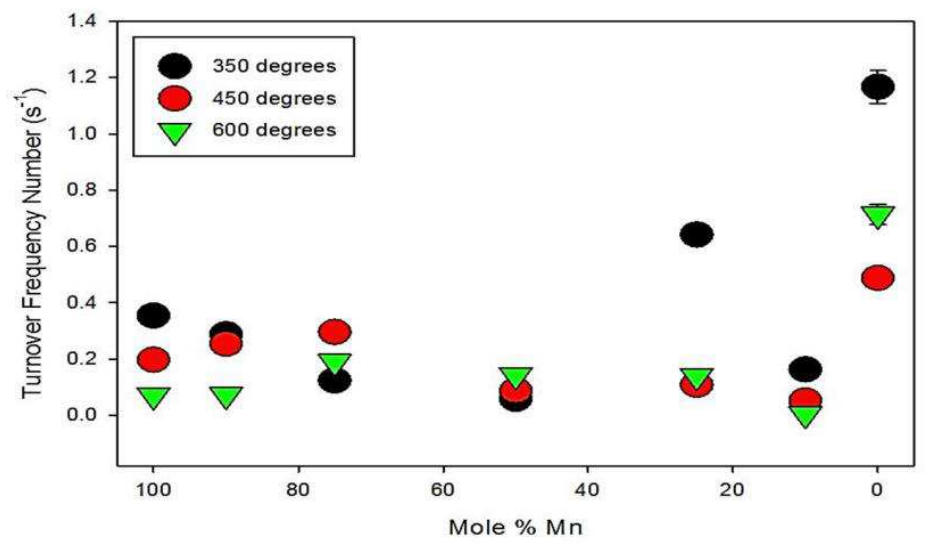

Figure 8. TOF values for various electrocatalysts considered in this study

Table 1.Comparison of TOF values of electrocatalysts (18)

\begin{tabular}{|c|c|c|}
\hline $\begin{array}{c}\text { Material (name In this } \\
\text { work) }\end{array}$ & Literature TOF values $\left(s^{-1}\right)$ & $\begin{array}{c}\text { TOF values }\left(s^{-1}\right) \\
\text { (This work) }\end{array}$ \\
\hline $\mathrm{Mn}_{2} \mathrm{O}_{3} \quad\left(\mathrm{Mn}\right.$ at $\left.600^{\circ} \mathrm{C}\right)$ & $0.035-0.055$ & 0.1 \\
\hline $\mathrm{Mn}_{3} \mathrm{O}_{4}\left(\mathrm{Mn}\right.$ at $\left.350{ }^{\circ} \mathrm{C}\right)$ & $\mathrm{n} / \mathrm{a}$ & 0.38 \\
\hline $\mathrm{RuO}_{2} \quad\left(\mathrm{Ru}\right.$ at $\left.350{ }^{\circ} \mathrm{C}\right)$ & 0.014 & 1.16 \\
\hline
\end{tabular}

The system with the largest known TOF for OER is called Photosystem II, an enzyme involved in the light dependent reactions of oxygenic photosynthesis, with a TOF value of ca. $1000 \mathrm{~s}^{-1}(18)$. Huge advances in this field are required to reach a TOF value comparable to that of Photosystem II.

From the results, as illustrated in Figure 8, the TOF values of the thermally prepared $\mathrm{Mn}_{\mathrm{x}} \mathrm{O}_{\mathrm{y}}$ electrocatalysts decrease with increasing temperature. However, the TOF value 
found for $\mathrm{Mn}_{\mathrm{x}} \mathrm{O}_{\mathrm{y}}$ at $600{ }^{\circ} \mathrm{C}$ is three times greater than the TOF values reported in the literature for $\mathrm{Mn}_{2} \mathrm{O}_{3}$ (16). Currently, to the author's knowledge, there are no TOF values, in the literature to compare the thermally prepared mixed $\mathrm{Mn}_{\mathrm{x}} \mathrm{O}_{\mathrm{y}} / \mathrm{RuO}_{\mathrm{x}}$ electrocatalysts. It is possible that TOF values could be increased further for thermally prepared $\mathrm{Mn}_{\mathrm{x}} \mathrm{O}_{\mathrm{y}} / \mathrm{RuO}_{\mathrm{x}}$ electrocatalysts by applying a higher or lower annealing temperature depending on the percentage of $\mathrm{Mn}_{\mathrm{x}} \mathrm{O}_{\mathrm{y}}$ and $\mathrm{RuO}_{2}$ used to produce the electrocatalysts.

The highest TOF value found in this study, with a value of $1.16 \mathrm{~s}^{-1}$, was obtained by the pure $(100 \%) \mathrm{RuO}_{\mathrm{x}}$ electrocatalyst, at an annealing temperature of $350{ }^{\circ} \mathrm{C}$. When compared to other $\mathrm{RuO}_{2}$ electrocatalysts in current literature, the TOF value of the $\mathrm{RuO}_{2}$ electrocatalyst, in this study, increased by a factor of one hundred (19-20).

\section{Conclusions}

In conclusion, we have developed a robust method of fabricating electrodes produced from pure $\mathrm{Mn}_{\mathrm{x}} \mathrm{O}_{\mathrm{y}}$, mixed ,90:10, 75:25, 50:50, $25: 75$ and 10:90, $\mathrm{Mn}_{\mathrm{x}} \mathrm{O}_{\mathrm{y}}: \mathrm{RuO}_{\mathrm{x}}$ and pure $\mathrm{RuO}_{\mathrm{x}}$ materials, over three different annealing temperatures, for the OER. Spectroscopic analysis indicated at the lower annealing temperatures $\mathrm{Mn}_{3} \mathrm{O}_{4}$ was formed, while $\mathrm{Mn}_{2} \mathrm{O}_{3}$ was formed at higher annealing temperatures. The amount of $\mathrm{Mn}_{2} \mathrm{O}_{3}$ seemed to increase with increasing annealing temperature causing a decrease in the overall electrocatalytic performance (including Tafel slopes, overpotentials and TOF values) of the OER electrocatalyst.

All mixed $\mathrm{Mn}_{\mathrm{x}} \mathrm{O}_{\mathrm{y}}: \mathrm{RuO}_{\mathrm{x}}$ electrocatalysts displayed Tafel slopes and initial OER overpotential values were lower than the pure $\mathrm{Mn}_{\mathrm{x}} \mathrm{O}_{\mathrm{y}}$ electrocatalysts. Those with a $75 \%$ - $25 \% \mathrm{Mn}$ content, at all annealing temperatures, exhibit similar Tafel slope values, indicating a diminishing electrocatalytic activity but with a vast change in price ; making the cheapest catalyst, i.e. the electrocatalyst with the higher percentage manganese oxide, the most economical.

Eight electrocatalysts, in this study, including all five mixed $\mathrm{Mn}_{\mathrm{x}} \mathrm{O}_{\mathrm{y}}: \mathrm{RuO}_{\mathrm{x}}$ at $350{ }^{\circ} \mathrm{C}$ and three of the five mixed $\mathrm{Mn}_{\mathrm{x}} \mathrm{O}_{\mathrm{y}}: \mathrm{RuO}_{\mathrm{x}}$ at $450{ }^{\circ} \mathrm{C}$, exhibited lower overpotential values than $\mathrm{RuO}_{2}$, the material with the lowest known overpotential, $0.2 \mathrm{~V}$. The $25: 75 \mathrm{Mn} / \mathrm{Ru}$ electrocatalyst at $450{ }^{\circ} \mathrm{C}$ produced an overpotential value of $0.16 \mathrm{~V}+/-0.01$, approximately $20 \%$ lower overpotential than $\mathrm{RuO}_{2}$.

The pure $\mathrm{Mn}_{\mathrm{x}} \mathrm{O}_{\mathrm{y}}\left(\mathrm{Mn}_{2} \mathrm{O}_{3}\right)$ annealed at $600{ }^{\circ} \mathrm{C}$ displayed TOF values approximately three times greater when compared to literature results. The pure $\mathrm{Mn}_{\mathrm{x}} \mathrm{O}_{\mathrm{y}}\left(\mathrm{Mn}_{3} \mathrm{O}_{4}\right)$ annealed at $350{ }^{\circ} \mathrm{C}$ exhibits a TOF value 4 times greater than the $\mathrm{Mn}_{2} \mathrm{O}_{3}$. The highest TOF value was obtained by the pure $(100 \%) \mathrm{RuO}_{\mathrm{x}}$ electrocatalyst at an annealing temperature of $350^{\circ} \mathrm{C}$, with a TOF value of $1.16 \mathrm{~s}^{-1}$.

\section{$\underline{\text { Acknowledgements }}$}

This publication has emanated in part from research conducted with the financial support of Science Foundation Ireland (SFI) under Grant Number SFI/10/IN.1/I2969. We would also like to thank the staff, particularly Dermot Daly, in the AML, CRANN for help with the SEM analysis. 


\section{$\underline{\text { References }}$}

1. Arno Bergmann, Ivelina Zaharieva, Holger Dau and Peter Strasser, Energy. Environ. Sci, 6, 2745 (2013).

2. P.Haussinger, R. Lohmuller and A.M. Watson, Ullmann's Encyclopaedia of Industrial Chemistry, Wiley- VCH Verlag GmbH and Co. KGaA, 2000.

3. K. Zeng and D. Zhang, Prog. Energy Combust. Sci., 36, 307 (2010).

4. H. Tributsch, Int. J. Hydrogen Energy, 33, 5911 (2008).

5. D. E. Hall, J. Electrochem. Soc., 130, 317 (1983).

6. D.Galizzioli, F. Tantardini, S. Trasatti, J. Appl Electrochem ,4,57-67(1974).

7. G.Lodi, C.De Asmundis, S. Ardizzone, E.Sivieri and S. Trasatti, Surface Technology, 14, 335-343(1981).

8. A.K.H Nohman, H.M. Ismail and G.A.M Hussein, Journal of Analytical and Applied Pyroylsis, 34, 265-278 (1995).

9. F. Barbir, PEM fuel cells: Theory and Practice, Elesvier, Walthem, USA (2013).

10. M. Morita, C. I wakura and H. Tamura, Electrochim. Acta, 24,357 (1979).

11. Z. Tian, P. M. Kouotou, N. Bahlawane and P.H. T. Ngamou, J. Phys Chem C, 117, $6218-6224$ (2013).

12. Y. Liu , Z. Liu , G. Wang , Appl. Phys. A. Mater,Sci Process, 76,1117-1120 (2003).

13. T.Rohani Bastami, M.H. Entezari, Ultrason. Sonochem, 19, 560-569 (2012).

14. S. Rui, W. Hong-Jun and . Shou- Hua, Chem. Res. Chinese Universities, 28, 4, 577-580.

15. M.E.G lyons and S. Floquet, Phys. Chem. Chem. Phys., 13, 5314 (2011).

16. L.D Burke and M.E.G Lyons, J.Electroanal. Chem, 198, 347(1986).

17. L.A. da Silva, V.A. Alves, M.A.P da Silva, S. Trasatti and J.F.C Boodts, Electrochimica Acta, 42, 2, 271-281 (1997).

18. M.E.G Lyons and S. Floquet, Phys. Chem. Chem. Phys., 13, 5314 (2011).

19. R.L Doyle, I.J Godwin, M.P Brandon and M.E.G Lyons, Phys. Chem. Chem. Phys, 15, 13737 (2013).

20. M. E.G. Lyons, R. L. Doyle, D. Fernandez, I. J. Godwin, M. P. Browne and A. Rovetta, Electrochem. Comm, 45, 60-62 (2014).

21. M. E.G. Lyons, R. L. Doyle, D. Fernandez, I. J. Godwin, M. P. Browne and A. Rovetta, Electrochem Comm, 45, 56-59 (2014). 